\title{
Photoreactivity of Bis-retinoid A2E Complexed with a Model Protein in Selected Model Systems
}

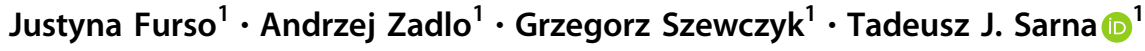

Published online: 12 September 2020

(c) The Author(s) 2020

\begin{abstract}
The bis-retinoid N-retinyl-N-retinylidene ethanolamine (A2E) is formed as a byproduct of visual cycle in retinal pigment epithelium (RPE). It contributes to golden-yellow fluorescence of the age pigment lipofuscin, which accumulates in RPE. Lipofuscin can generate a variety of reactive oxygen species (ROS) upon blue-light excitation. Although in model systems photoreactivity of A2E has been determined to be low, this bis-retinoid exhibited significant phototoxicity in RPE cells in vitro. Although the mechanism of A2E-mediated phototoxicity remains mostly unknown, we hypothesize that formation of A2E-adducts with different biomolecules may play an important role. In this study, we investigated the photochemical reactivity of A2E and its complex with bovine serum albumin (BSA) using UV-Vis absorption and emission spectroscopy, EPR-spin trapping, EPR-oximetry, time-resolved singlet oxygen phosphorescence, and the fluorogenic CBA probe. Our data show that A2E after complexation with this model protein photogenerated an increased level of ROS, particularly singlet oxygen. We also demonstrated the ability of A2E to oxidize BSA upon excitation with blue light in aqueous model systems. The data suggest that pyridinium bis-retinoid could oxidatively modify cellular proteins under physiological conditions.
\end{abstract}

Keywords A2E $\cdot$ Photochemical reactivity $\cdot$ Protein oxidation $\cdot$ Reactive oxygen species $\cdot$ Singlet oxygen $\cdot$ EPR-Spin trapping

\section{Introduction}

It has been postulated that the amorphous pigment lipofuscin, which accumulates with age in retinal pigment epithelium (RPE), mediates photochemical reactions, which can contribute to oxidative stress in the outer retina. It has been documented that lipofuscin, can generate, upon excitation with blue light, reactive oxygen species (ROS) [1, 2], participate in lipid and protein oxidation, inactivate lysosomal and antioxidant enzymes [3-6] and inhibit phagocytic activity of RPE cells in vitro [7]. Chronic oxidative stress in RPE cells may contribute to the development of

Supplementary information The online version of this article (https:// doi.org/10.1007/s12013-020-00942-1) contains supplementary material, which is available to authorized users.

Tadeusz J. Sarna

tadeusz.sarna@uj.edu.pl

1 Department of Biophysics, Faculty of Biochemistry, Biophysics and Biotechnology, Jagiellonian University, 30-387

Krakow, Poland variety of retinal degenerative diseases $[8,9]$ including agerelated macular degeneration, in which the role of lipofuscin has been generally considered [10-13]. Lipofuscin is a composite granule containing lipids, proteins and several pigments which absorb blue light [14]. One of such chromophores is N-retinylidene-N-retinylethanolamine, called A2E (Scheme 1), formed mostly nonenzymatically from the metabolites of the visual pigment and lipid components of photoreceptor outer segment membranes [15]. This pyridinium bis-retinoid has been identified as an important fluorescent chromophore of the RPE age pigment [16-18]. Biosynthesis of A2E takes place in RPE, where lipofuscin granules accumulate with senescence. The concentration of A2E in RPE may reach $20 \mu \mathrm{M}$ in advanced age [19]. A2E is composed of two hydrophobic polyene side-chains and a polar positively charged pyridinium moiety. Such structure results in detergent-like nature of the compound. As a result, this bis-retinoid may act destructively in RPE cells even without light exposure by disrupting organelle membranes, such as lysosomal membranes. It was also demonstrated that incorporation of A2E into model membranes accelerated cholesterol displacement from lipid bilayers. If such a phenomenon occurs in RPE cells, it would result in 


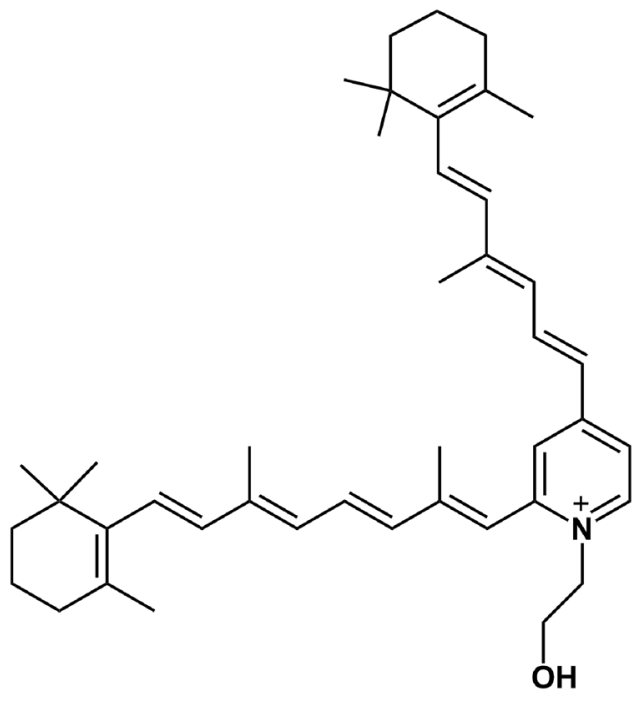

Scheme 1 The structure of A2E

accumulation of free and esterified cholesterol in the cells [20]. The disturbed degradative functions of RPE lysosomes mediated by A2E was explained by inhibition of the ATPdriven proton pump in organelle membranes [21, 22].

$\mathrm{A} 2 \mathrm{E}$ is also known to be photoreactive. It absorbs light in the UV and visible region and its absorption spectrum in organic solvents features two distinct maxima at 336 and $439 \mathrm{~nm}$ [23]. It has been postulated that $\mathrm{A} 2 \mathrm{E}$ is at least partially responsible for photoreactivity and phototoxicity of lipofuscin. Interestingly, although in simple model systems the photochemical reactivity of A2E was shown to be low [24], it exhibited significant phototoxicity in RPE cells in vitro $[25,26]$.

The ability of A2E to photoinduce peroxidation of proteins has not been systematically investigated. However, such a process may have significant implications, especially in the case of RPE proteins responsible for the cell architecture. We believe that oxidative modifications of cytoskeletal proteins may have adverse effect on both morphology and nanomechanical properties of RPE cells [27, 28]. Recently, Wiktor et al. [29]. have demonstrated that sublethal or weakly lethal photic stress, mediated by human RPE lipofuscin granules, affected nanomechanical properties of ARPE-19 cells. It turned out that the photogenerated oxidative stress brought about oxidation of cellular proteins, disrupted the cell cytoskeleton, and modified the cell elasticity. It is important to emphasize that the role of A2E in these phenomena remains unknown. The accumulating in the retinal tissue A2E may form complexes with proteins and other cellular constituents that could modify this bis-retinoid photoreactivity and phototoxicity. Therefore, it is relevant to examine how complexation with a model protein changes the ability of $\mathrm{A} 2 \mathrm{E}$ to photogenerate ROS.
In this study, we investigated the effect of bovine serum albumin (BSA) on photochemical reactivity of A2E using EPR-spin trapping, EPR-oximetry, and singlet oxygen detection. We also analyzed the capability of A2E to oxidize BSA using the sensitive coumarin boronic acid (CBA) probe and fluorescence measurements.

\section{Materials and Methods}

\section{Chemicals}

The following chemicals were obtained from Sigma-Aldrich (Steinheim, Germany or St. Louis, MO, USA): all-trans retinal, ethanolamine, trifluoroacetic acid (TFA), methanol, ethanol, catalase, superoxide dismutase (SOD), sodium azide, 1,4-diazabicyclo[2.2.2] octane (DABCO), 4-(1,1,3,3-tetramethylbutyl)phenyl-polyethylene glycol (TX-100), chelating resins Chelex 100, diethylenetriaminepentaacetic acid (DTPA), Tetra(4-N,N,N-trimetylanilinium) porphine (TMAP), and deuterium oxide. BSA was purchased from BioShop Canada (Burlington, Canada). 4-Protio-3-carbamoyl-2,2,5,5tetraperdeuteromethyl-3-pyrroline-1-yloxy (mHCTPO) was a gift from Professor H. J. Halpern (University of Chicago, Chicago, IL). n-5,5-Dimethyl-1-Pyrroline-N-Oxide (DMPO) was obtained from Dojindo Laboratories (Kumamoto, Japan). Dodecyl- $\beta$-D-maltopyranoside (DDM) was purchased from Anatrace Products LLC (Maumee, OH, USA). Disodium hydrogen phosphate dodecahydrate $\left(\mathrm{Na}_{2} \mathrm{HPO}_{4} \times 12 \mathrm{H}_{2} \mathrm{O}\right)$, potassium dihydrogen phosphate $\left(\mathrm{KH}_{2} \mathrm{PO}_{4}\right)$, hydrochloric acid $(\mathrm{HCl})$, acetic acid, potassium chloride $(\mathrm{KCl})$, sodium chloride $(\mathrm{NaCl})$, acetonitrile and dimethyl sulfoxide (DMSO) were purchased from Polskie Odczynniki Chemiczne (Gliwice, Poland). CBA indicator was a gift from Professor A. Sikora (Institute of Applied Radiation Chemistry, Technical University of Lodz, Poland). All chemicals were of highest purity and used as supplied. All working solutions were prepared with double distilled water and stored at $4{ }^{\circ} \mathrm{C}$ or at room temperature.

\section{Synthesis and Purification of A2E}

A2E was synthesized as previously reported by Parish et al. [30]. Two equivalents of all-trans retinal, one equivalent of ethanolamine and one equivalent of acetic acid in ethanol where stirred at room temperature for $48 \mathrm{~h}$ in the dark. A2E was pre-purified by silica gel chromatography and then purified by HPLC (Shimadzu, Japan) on the semipreparative Cosmosil 5C18 RP column, $250 \times 10 \mathrm{~mm}$ (Beckman Coulter, USA) with the following gradients of acetonitrile/water $(0.1 \%$ TFA): $90-100 \%$ for $0-10 \mathrm{~min}$, $100 \%$ acetonitrile $(0.1 \% \mathrm{TFA}$ ) for $10-35 \mathrm{~min}$ (flow rate $4 \mathrm{~mL} / \mathrm{min}$ ). Elution of the A2E was monitored at $430 \mathrm{~nm}$ 
and its retention time was $9 \mathrm{~min}$. Identification of A2E was determined by UV-Vis spectrophotometry (Hitachi U2900, Japan). Stock solution of A2E was prepared in acetonitrile or methanol and kept in $-80^{\circ} \mathrm{C}$.

\section{Preparation of A2E-BSA Complexes}

BSA stock solution was prepared in $\mathrm{H}_{2} \mathrm{O}$ or $\mathrm{D}_{2} \mathrm{O}$ and kept prior to use in $4{ }^{\circ} \mathrm{C}$. A2E-BSA complex was prepared by adding a small volume of concentrated $\mathrm{A} 2 \mathrm{E}$ in acetonitrile directly to a solution of BSA in water, mixed vigorously and kept on ice. In some experiments A2E and BSA were suspended in micellar model system containing $1 \%$ of TX-100 or $1 \%$ of DDM in $\mathrm{H}_{2} \mathrm{O}$ or $\mathrm{D}_{2} \mathrm{O}$. Final concertation of $\mathrm{A} 2 \mathrm{E}$ and BSA in a non-micellar and micellar model system, depending on the exact experiment, was $10 \mu \mathrm{M}$ or $50 \mu \mathrm{M}$ and $20 \mu \mathrm{M}$ or $100 \mu \mathrm{M}$, respectively.

\section{Oxygen Consumption Measurements}

Rates of photoconsumption of oxygen were obtained by measuring kinetics of oxygen concentration changes in irradiated samples by EPR oximetry, according to method described elsewhere [31, 32]. Suspension of A2E $(50 \mu \mathrm{M})$ or/ and BSA $(100 \mu \mathrm{M})$ in water/micellar system containing $100 \mu \mathrm{M}$ mHCTPO used as an oxygen-sensitive spin probe, was placed in a standard EPR flat quartz cell and positioned in a resonant cavity equipped with an optical window. Oxygen consumption was examined during in situ irradiation of samples with blue light $\left(30 \mathrm{~mW} / \mathrm{cm}^{2}\right)$ derived from a $300 \mathrm{~W}$ high pressure compact arc xenon lamp (Cermax, PE300CE-13FM/Module300W, Perkin-Elmer) equipped with a water filter, heat reflecting hot mirror, and dichroic filter transmitting light at a range of 402-508 $\mathrm{nm}$. To examine a possible role of superoxide anion, in the photo-induced oxygen uptake in samples containing $\mathrm{A} 2 \mathrm{E} / \mathrm{BSA}$ in $\mathrm{D}_{2} \mathrm{O}$, EPR oximetry was also carried out after addition of $500 \mathrm{U} / \mathrm{mL}$ of SOD. Such samples were irradiated with $10 \mathrm{~mW} / \mathrm{cm}^{2}$ blue light. The EPR measurements were performed at ambient temperature using a Bruker EMX-AA EPR spectrometer (Bruker BioSpin, Rheinstetten, Germany) operating at 9.5 GHz with $100-\mathrm{kHz}$ field modulation. EPR spectra were registered at following instrument settings: microwave power $1 \mathrm{~mW}$, modulation amplitude $0.006 \mathrm{mT}$, scan width $0.5 \mathrm{mT}$, and scan time $12 \mathrm{~s}$. Rates of oxygen uptake were determined by linear fitting to initial points of the oxygen depletion plot.

\section{Singlet Oxygen Measurements}

Time-resolved phosphorescence of ${ }^{1} \mathrm{O}_{2}$ was detected at $1270 \mathrm{~nm}$ in $1 \%$ DDM-D $2 \mathrm{O}$ system and $\mathrm{D}_{2} \mathrm{O}$. Concentrations were adjusted to obtain $\mathrm{OD}=0.17$ at $422 \mathrm{~nm}$ for both the A2E sample and reference photosensitizer. Samples were measured in $10 \mathrm{~mm}$ fluorescence cuvette (QA-1000, Helma, Germany) and excited with $422 \mathrm{~nm}$ pulses of $3.6 \mathrm{~ns}$ duration emitted by Nd:YAG laser (NT242, Expla, Lithuania) operating at $1 \mathrm{kHz}$ repetition rate. To adjust photoexcitation energy, the laser beam was attenuated with three pieces of a wire mesh (light transmission of each piece $\sim 35 \%$ ). The exciting laser beam was perpendicular to the detection path, and the luminescence signals were recorded in a photon counting mode using a thermoelectric-cooled NIR PMT unit (Model H1033045, Hamamatsu, Japan) equipped with a 1100-nm cutoff filter and additional selected narrow-band filter (NB series, NDC Infrared Engineering LTD, UK). The data acquisition was performed using a computer-mounted PCI-board multichannel scaler (NanoHarp 250, PicoQuant $\mathrm{GmbH}$, Germany). Data were collected for $15 \mathrm{~s}$. The data analysis was performed by a custom-written software and included first-order luminescence decay fitting by the Levenberg-Marquardt algorithm. Determination of singlet oxygen quantum yield $\left(\phi_{\Delta}\right)$ generated by A2E in $1 \%$ DDM$\mathrm{D}_{2} \mathrm{O}$ was carried out relative to TMAP (Tetra(4-N,N,N-trimetylanilinium)porphine) as the reference sensitizer, with a $\phi_{\Delta}=0.73[33]$.

\section{EPR-spin Trapping}

For detection of superoxide anion, 5,5-dimethyl-1-pyrrolineN-oxide (DMPO; $100 \mathrm{mM}$ ) was used as a spin trap. Photoinduced generation of superoxide was monitored in A2E or A2E/BSA samples dissolved in 80\% DMSO. DMPO has a low efficacy for trapping superoxide radicals in aqueous media and the DMPO-OOH adduct is quite unstable [34]. However, since superoxide has nucleophilic character in aprotic solvents [35], their application facilitates its spin trapping. Therefore, the superoxide spin trapping experiments were carried out using high concentration of DMPO and the highest possible DMSO content (80\%). The other $20 \%$ of the sample solvent was water used for preparation of BSA and DMPO stock solutions. Samples with and without $500 \mathrm{U} / \mathrm{ml}$ of SOD in quartz EPR flat cells were place in resonant cavity and irradiated with blue light. To examine possible effects of singlet oxygen, spin trapping experiments were also carried out after the addition of $10 \mathrm{mM}$ sodium azide or $10 \mathrm{mM}$ DABCO, efficient quenchers of this ROS [36]. The photo-induced formation of free radicals was inferred from the observed accumulation of characteristic spin adducts, and their identification was confirmed by simulation of the experimental spectra using WinSIM software. Irradiating light, with similar parameters, was derived from the same light source as that used in oxygen photoconsumption experiments. The EPR samples were run using a microwave power $10 \mathrm{~mW}$, modulation amplitude $0.05 \mathrm{mT}$, sweep width $12 \mathrm{mT}$, and sweep time $42 \mathrm{~s}$. 


\section{Determination of Protein Oxidation by CBA Assay}

Photooxidation of albumin in micellar and non-micellar model systems mediated by A2E was determined by monitoring the conversion of the nonfluorescent CBA into fluorescent 7-hydroxycoumarin $(\mathrm{COH})$ as described elsewhere [37, 38]. Immediately after blue-light irradiation $\left(440 \mathrm{~nm} ; 60 \mathrm{~mW} / \mathrm{cm}^{2}\right)$, control samples with BSA $(100 \mu \mathrm{M})$ and samples containing A2E $(50 \mu \mathrm{M})$, were incubated with catalase $(250 \mathrm{U} / \mathrm{ml})$ for $5 \mathrm{~min}$ then frozen in liquid nitrogen. Some samples in $\mathrm{D}_{2} \mathrm{O}$-micellar systems were blue lightirradiated with or without $5 \mathrm{mM}$ sodium azide. All samples were transferred at the same time into black 96-well plates and incubated with phosphate buffer (PB) $(50 \mathrm{mM}, \mathrm{pH} 7.4)$, DTPA $(100 \mu \mathrm{M})$, CBA $(200 \mu \mathrm{M})$, and catalase $(250 \mathrm{U} / \mathrm{ml})$. Fluorescence emission of the formed $\mathrm{COH}$ in irradiated samples was measured at $465 \mathrm{~nm}$ after excitation at $360 \mathrm{~nm}$, using the ClarioStar plate reader (BMG Labtech, USA). Due to low reactivity of the probe with protein hydroperoxides, the fluorescence signal was recorded at $10 \mathrm{~min}$ intervals for $20 \mathrm{~h}$. Fluorescence was plotted against time as shown in Fig. 8. The extent of protein oxidation was given as a concentration of the albumin hydroperoxides calculated from the crossing points of lines fitted to the initial increase of the fluorescent intensity and the last points of the increase of fluorescent intensity of the same sample and normalized to the hydrogen peroxide calibration curve. Samples for the calibration were prepared in similar manner as examined samples except the catalase addition. The experiments were repeated minimum two times.

\section{Fluorescence Measurements}

Emission spectra of A2E and BSA in PB were recorded in $10 \mathrm{~mm}$ fluorescence quartz cuvette (QA-1000, Helma, Germany) containing a magnetic stirrer and sealed with a rubber septum using LS55 spectrofluorimeter (PerkinElmer, Inc., USA). Prior the measurement, the sample was stirred under argon (gas was streaming on the liquid surface) for 30 min. Emission spectra for BSA and A2E were recorded at excitation wavelength $278 \mathrm{~nm}$ (excitation slit $10 \mathrm{~nm} /$ emission slit $3 \mathrm{~nm}$ ) and $450 \mathrm{~nm}$ (excitation/emission slit $10 \mathrm{~nm})$, respectively.

The interaction of $\mathrm{A} 2 \mathrm{E}$ and $\mathrm{BSA}$ was examined in the samples prepared in $\mathrm{PB}\left(\mathrm{H}_{2} \mathrm{O}\right)$ or $\mathrm{PB}\left(\mathrm{H}_{2} \mathrm{O}\right)$ with $0.25 \%$ DDM. A total of $5 \mu \mathrm{M}$ BSA was titrated with $0.575 \mu \mathrm{M}$ A2E portions of stock solution in acetonitrile for a final A2E concentration of $\sim 20 \mu \mathrm{M}$. In this range of the concentrations used, optical density (OD) of the samples was maintained at 0.2-0.4. After argon saturation the fluorescence spectra of the BSA sample with increasing concertation of $\mathrm{A} 2 \mathrm{E}$ was recorded. The binding of $\mathrm{A} 2 \mathrm{E}$ to $\mathrm{BSA}$ was investigated using the exponential decay fitted to the intensity of the BSA emission at fluorescence maximum plotted against the concertation of titrated A2E. Fitting the data to the nonlinear regression allowed us to obtain a dissociation constant $\left(K_{\mathrm{d}}\right)$ of the binding pair. Quenching of the BSA fluorescence was observed at 350 and $335 \mathrm{~nm}$ for BSA in the solution and in the micellar system, respectively. In order to verify the negligible effect of the acetonitrile on the BSA emission, fluorescence of the protein was also measured by repeating the titration without the ligand.

Intrinsic fluorescence of BSA was measured before and after photolysis, using samples prepared in $\mathrm{PB}\left(\mathrm{D}_{2} \mathrm{O}\right)$. In total, $50 \mu \mathrm{M}$ A2E and $100 \mu \mathrm{M}$ BSA were irradiated with $440 \mathrm{~nm}\left(60 \mathrm{~mW} / \mathrm{cm}^{2}\right)$ for selected time intervals. Samples were gently stirred and temperature was maintained at $4{ }^{\circ} \mathrm{C}$ during the photolysis. Before and after irradiation, $300 \mu \mathrm{L}$ of the sample was diluted to obtain $10 \mu \mathrm{M} \mathrm{A} 2 \mathrm{E}$ and $20 \mu \mathrm{M}$ $\mathrm{BSA}$, and the fluorescence spectra were recorded after excitation at 278,325 , and $365 \mathrm{~nm}$, according to absorption maxima of tryptophan, $\mathrm{N}^{\prime}$-formylkynurenine, and kynurenine, respectively [39].

\section{Circular Dichroism (CD)}

CD spectra of the samples containing $100 \mu \mathrm{M}$ BSA or $100 \mu \mathrm{M}$ BSA and $50 \mu \mathrm{M}$ A2E in $\mathrm{PB}-\mathrm{D}_{2} \mathrm{O}$ were recorded before and after irradiation with $440 \mathrm{~nm}$ light $\left(60 \mathrm{~mW} / \mathrm{cm}^{2}\right)$ for selected time intervals. CD measurements were performed in the Department of Physical Biochemistry (Faculty of Biochemistry, Biophysics and Biotechnology, Jagiellonian University), using a Jasco J-710 spectropolarimeter (Jasco Analytical Instruments, USA). The spectra were collected in a range of $180-250 \mathrm{~nm}$ with a $1 \mathrm{~nm}$ data pitch, a $50 \mathrm{~nm} \mathrm{~min}^{-1}$ scanning speed, a $2 \mathrm{~s}$ response time and a $2 \mathrm{~nm}$ bandwidth and averaged over three acquisitions. Protein samples were measured in a cuvette with a $0.01 \mathrm{~mm}$ light path. Buffer used for sample preparation was used as a blank. The contents of secondary structure were calculated based on experimental data and Prot 4 reference base using Jasco Secondary Structure Estimation (JSSE) software.

\section{Photodegradation of A2E}

Photodegradation of air-equilibrated or saturated with argon for $2.5 \mathrm{~h}$ samples, containing $50 \mu \mathrm{M}$ A2E in $1 \% \mathrm{DDM}$ in $\mathrm{PB}-\mathrm{D}_{2} \mathrm{O}$ or in the presence of $100 \mu \mathrm{M}$ BSA in PB- $\mathrm{D}_{2} \mathrm{O}$, was induced by irradiation with blue light, employing $440 \mathrm{~nm}$ LED $\left(60 \mathrm{~mW} / \mathrm{cm}^{2}\right)$, and monitored by UV-Vis spectroscopy (Hitachi U-2900, Japan). During the photolysis samples were gently stirred. Samples which were blue-light irradiated under air were diluted five times for the absorption measurements. 


\section{Results and Discussion}

A2E is not soluble in water, therefore $1 \%$ DDM, forming micellar system, was used. Absorption spectrum of DDMsolubilized A2E is shown in Fig. 1. The more pronounced peak is localized at $438 \mathrm{~nm}$. Addition to such sample $0.1 \mathrm{mM}$ BSA, causes broadening and a small hypsochromic shift of the A2E absorption, which is particularly evident for the longer wavelength peak. Similar spectrum is also observed for $\mathrm{A} 2 \mathrm{E}$ in the presence of $0.1 \mathrm{mM} \mathrm{BSA}$, without the detergent; however, the sample may be partially aggregated, which is suggested by the apparent absorption in the region above $550 \mathrm{~nm}$ probably due to light scattering. The absorption changes induced by the addition of BSA suggest that A2E forms noncovalent complexes with BSA.

\section{Blue Light-induced Oxygen Consumption}

The A2E photoreactivity and the effect of complexation with protein was analyzed in simple model systems by measuring photo-induced oxygen uptake in the presence and absence of BSA. Before irradiation, A2E was incubated with BSA for $5 \mathrm{~min}$. In control samples, containing BSA with $\mathrm{D}_{2} \mathrm{O}$-micelles, blue light induced very slow oxygen consumption with the rate $0.4 \mu \mathrm{M} / \mathrm{min}$ (Fig. 2a, b). In samples containing A2E solubilized in $\mathrm{D}_{2} \mathrm{O} /$ Triton X-100 micelles (without BSA) the rate of oxygen photouptake was at least threefold higher, and addition of BSA further accelerated the observable rate of oxygen photoconsumption. When micellar system was used, oxygen photoconsumption in $\mathrm{H}_{2} \mathrm{O}$, compared to $\mathrm{D}_{2} \mathrm{O}$, was almost twofold slower and azide reduced the rate of oxygen consumption by almost a factor of five, suggesting that the observed oxidation process might involve singlet oxygen (Fig. 3a, b). Without Triton X-100, the rate of oxygen photouptake in samples containing $0.1 \mathrm{mM}$ BSA, was 2.5 times higher than that in micellar systems (Fig. 4). It indicates that

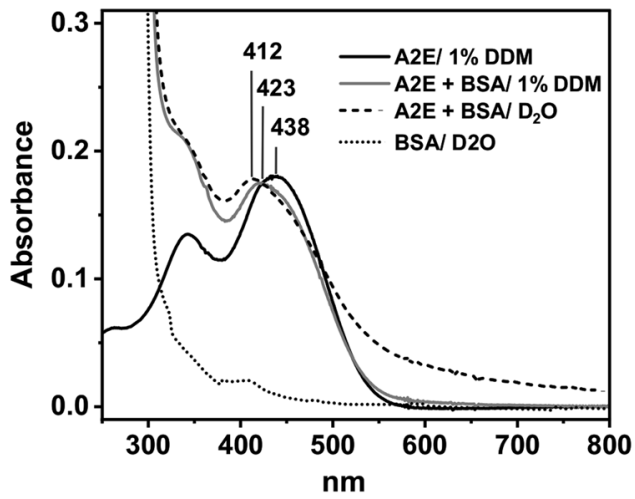

Fig. 1 UV-Vis spectra of A2E in D2O/1\% DDM (black line), with $\mathrm{BSA}$ in $\mathrm{D}_{2} \mathrm{O}$-micellar model system (gray line), A2E-BSA complex in $\mathrm{D}_{2} \mathrm{O}$ (dashed line) and $\mathrm{BSA}$ in $\mathrm{D}_{2} \mathrm{O}$ (dotted line) complexation of A2E by BSA facilitates oxidation of the protein. The lower rate of oxygen photoconsumption observed in micellar systems containing BSA/A2E, suggests that the detergent could disturb complexation of BSA with A2E. The fact that azide had almost no effect on oxygen photoconsumption in samples containing BSA-A2E complexes (without Triton X-100) may suggest no role or only a minor role of singlet oxygen in the photooxidation of BSA complexed with A2E. It is possible that other ROS are involved. Indeed, our data indicate that superoxide anion photogenerated by A2E was involved in BSA oxidation mediated by A2E (vide infra). Since oxygen photoconsumption was slightly faster when SOD was added to the suspension of BSA and A2E in $\mathrm{D}_{2} \mathrm{O}$ (Supplementary Fig. 5S), it suggests competition between the interaction of superoxide with protein and SOD-catalyzed dismutation. However, the role of singlet oxygen cannot unambiguously be ruled out. Thus, the very weak inhibition of oxygen photoconsumption in the presence of $10 \mathrm{mM}$ azide (Fig. 4), even if the process was mediated by singlet oxygen, could be due to limited accessibility of the protein sites where the binding with $\mathrm{A} 2 \mathrm{E}$ occurs, particularly for negatively charged azide ions. It is expected that these binding sites should be more accessible to water molecules, which may explain the effect of $\mathrm{H}_{2} \mathrm{O} / \mathrm{D}_{2} \mathrm{O}$ exchange. The observed enhancement of oxygen photoconsumption after exchanging $\mathrm{H}_{2} \mathrm{O}$ for $\mathrm{D}_{2} \mathrm{O}$ is consistent with the involvement of singlet oxygen, taking into account that in $\mathrm{D}_{2} \mathrm{O}$ singlet oxygen lifetime is about 15-fold longer than in $\mathrm{H}_{2} \mathrm{O}$ [40, 41].

Although A2E is considered to be a poor singlet oxygen generator [42, 43], it was reported by Sparrow and collaborators that singlet oxygen, photogenerated by this bisretinoid, contributed to its photoreactivity [44] and phototoxicity [45]. In a study by Pawlak et al. [24] photo-induced oxygen uptake mediated by $\mathrm{A} 2 \mathrm{E}$, measured in a suspension of liposomes, containing unsaturated lipids, was modulated inversely by azide and histidine, which are physical and chemical quenchers of singlet oxygen, respectively [36]. It suggests the involvement of singlet oxygen, consistent with results obtained in this study, when micellar system was used. On the other hand, in complexes with proteins, such as BSA, A2E may operate via alternative mechanism, in which other ROS are involved.

\section{Singlet Oxygen Measurements}

Time-resolved measurements of phosphorescence in $1 \%$ DDM- $\mathrm{D}_{2} \mathrm{O}$ indicate that $\mathrm{A} 2 \mathrm{E}$ is able to photogenerate singlet oxygen, with quantum yield estimated to be $1.9 \%$. Micelles create specific microenvironment allowing the lipophilic A2E to dissolve. While aggregation of A2E, observed in water, reduces substantially the yield and 
Fig. 2 Blue light-induced oxygen uptake in the micellar model system containing $50 \mu \mathrm{M}$ A2E, $100 \mu \mathrm{M}$ BSA, or a suspension of both in $1 \%$ TX100 (a) and determined rates of oxygen photoconsumption (b)
Fig. 3 Dark and blue lightinduced oxygen uptake in the micellar model system containing $50 \mu \mathrm{M} \mathrm{A} 2 \mathrm{E}$ and $100 \mu \mathrm{M}$ BSA in $\mathrm{H}_{2} \mathrm{O}$ or $\mathrm{D}_{2} \mathrm{O}$ (a) and determined rates of oxygen photoconsumption (b)
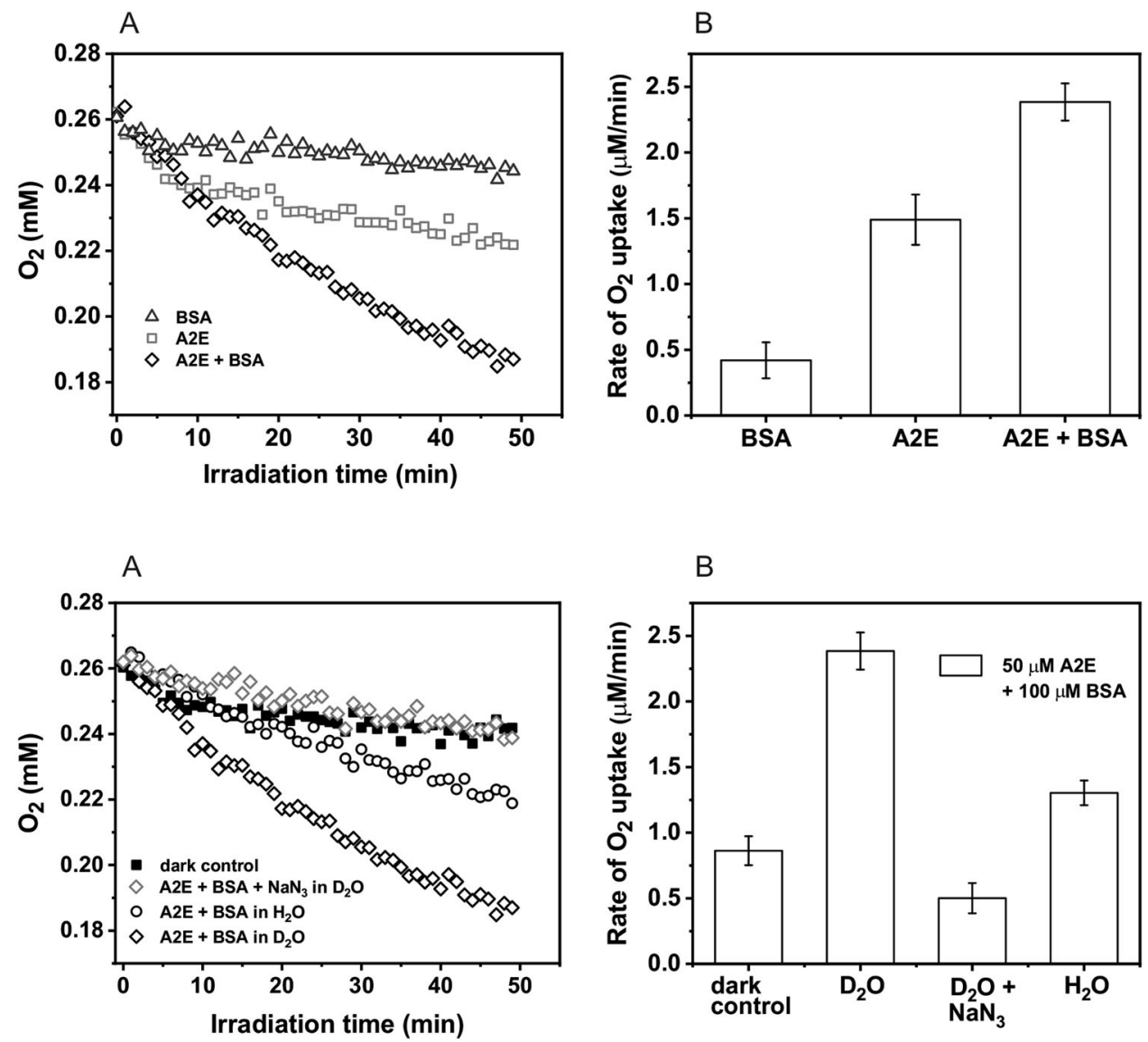

Fig. 4 Blue light-induced oxygen uptake of A2E-BSA complex in $\mathrm{D}_{2} \mathrm{O}$ (a) and the comparison of oxygen consumption rates of $\mathrm{A} 2 \mathrm{E}$ and BSA in $\mathrm{D}_{2} \mathrm{O}$-micellar system with the $\mathrm{A} 2 \mathrm{E}$ and $\mathrm{BSA}$ in $\mathrm{D}_{2} \mathrm{O}$ non-micellar system (b)
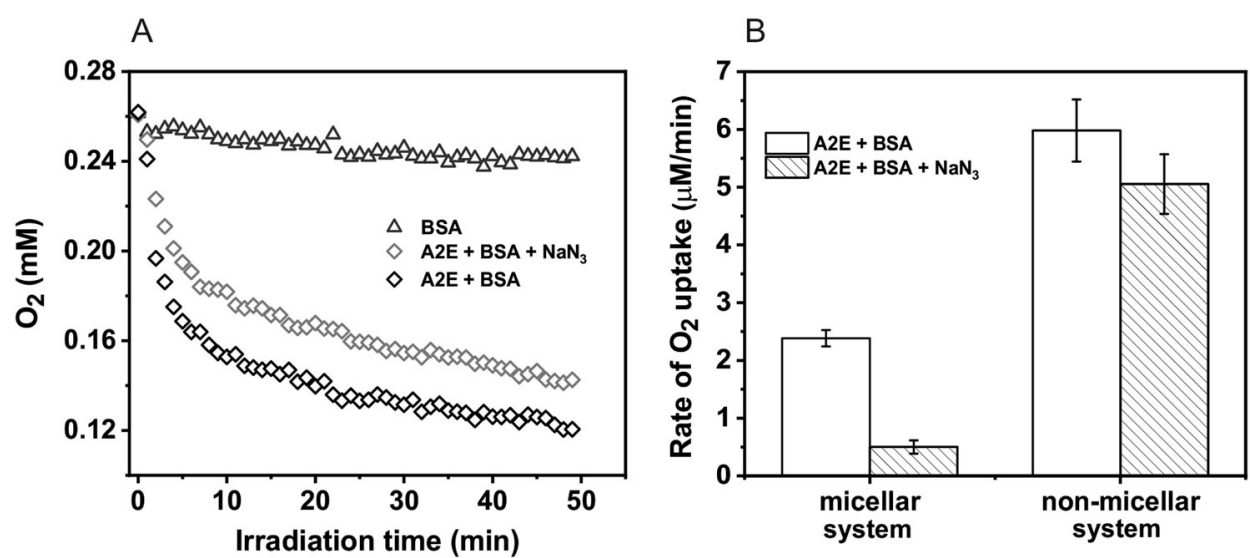

lifetime of the chromophore excited triplet state, deaggregation of A2E increases its triplet state lifetime facilitating photogeneration of singlet oxygen. Due to higher solubility of oxygen in lipids, local concentration of dioxygen could be greater in micelles than in water, increasing the chance of $\mathrm{A} 2 \mathrm{E}$ triplet state to form singlet oxygen. Singlet oxygen intrinsic lifetime is also longer in lipids/membranes in comparison to water $(\sim 15 \mu$ s compared to $3.5 \mu$ s in water). BSA greatly reduced the intensity of singlet oxygen phosphorescence and its lifetime (Fig. 5). The residual phosphorescence detected at $1270 \mathrm{~nm}$, indicates that the yield of singlet oxygen photogenerated by the A2E complex with BSA is significantly lower than that by $\mathrm{A} 2 \mathrm{E}$ in a micellar system. In addition, the lifetime of singlet oxygen photogenerated by BSA-A2E is reduced almost threefold, compared to the micellar system without BSA. This is due to efficient quenching by the protein, consistent with the reported corresponding rate constant being $5 \times 10^{8} \mathrm{M}^{-1} \mathrm{~s}^{-1}[46]$. 


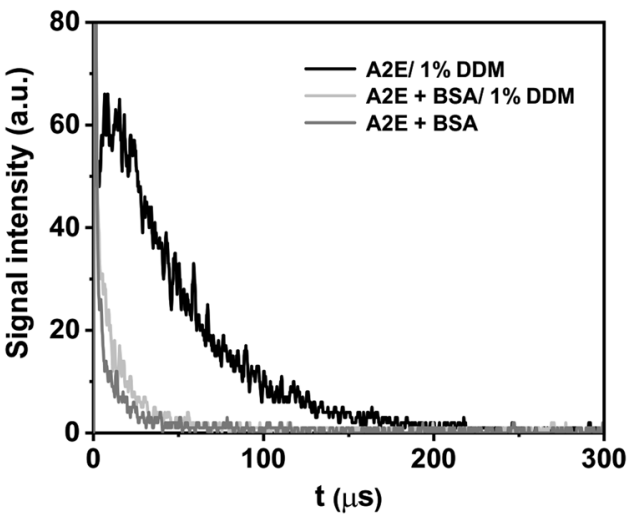

Fig. 5 Time-resolved luminescence induced by photoexcitation of $\mathrm{A} 2 \mathrm{E}$ in $\mathrm{D}_{2} \mathrm{O}: 1270 \mathrm{~nm}$ luminescence decay detected in A2E samples in $\mathrm{D}_{2} \mathrm{O} / \mathrm{DDM}$ (black line) with addition of $100 \mu \mathrm{M}$ BSA (light gray line) and with $100 \mu \mathrm{M}$ BSA but without DDM (lower dark gray line). A2E was excited with $422 \mathrm{~nm}, 360 \mu \mathrm{J}$ laser pulses

\section{Generation of Free Radicals by Photoexcited A2E}

Irradiation of $\mathrm{A} 2 \mathrm{E}$ in a mixture of DMSO and water, in the presence of the DMPO spin trap, with blue light-induced generation of a spin adduct with hyperfine splitting consistent with trapping of superoxide anion [47]. It is shown in Fig. 6a, which compares the experimental and simulated EPR spectra. When BSA was added to A2E, the detected EPR signal (Fig. $6 \mathrm{~b})$ exhibited additional spectral features suggesting the formation of more than one spin adduct. Simulation of the observed spectrum, assuming the presence of DMPO adduct with superoxide and an unidentified spin adduct with hyperfine splitting typical for a nitrogen-centered radical [48] (Fig. $6 c$ ), indicates an acceptable fit of the experimental and simulated spectra. The kinetics of the DMPO spin adduct accumulation during sample irradiation indicates that the radical formation rate is enhanced by a factor of 1.8 when BSA was added (Fig. 7a, b). In addition, SOD reduced the rate of DMPO-OOH accumulation by a factor of 2.5.

Previous studies using EPR-spin trapping $[49,50]$ and pulse radiolysis [51] also indicated that $\mathrm{A} 2 \mathrm{E}$ could generate superoxide anion in simple model systems. Pawlak et al. [24] demonstrated that A2E photogenerated superoxide radical four times faster than its photoreactive precursor, alltrans retinal. Nevertheless, the efficiency of superoxide anion photoproduction by A2E was determined to be very low-0.0003. Those data are consistent with the results obtained in this study. Spectral parameters of the detected spin adduct and the inhibitory effect of superoxide anion dismutase (SOD) on evolution of the spin adduct indicate that the main free radical photogenerated by $\mathrm{A} 2 \mathrm{E}$ was superoxide anion. Interestingly, our data also showed that photogeneration of radicals mediated by $\mathrm{A} 2 \mathrm{E}$ was enhanced
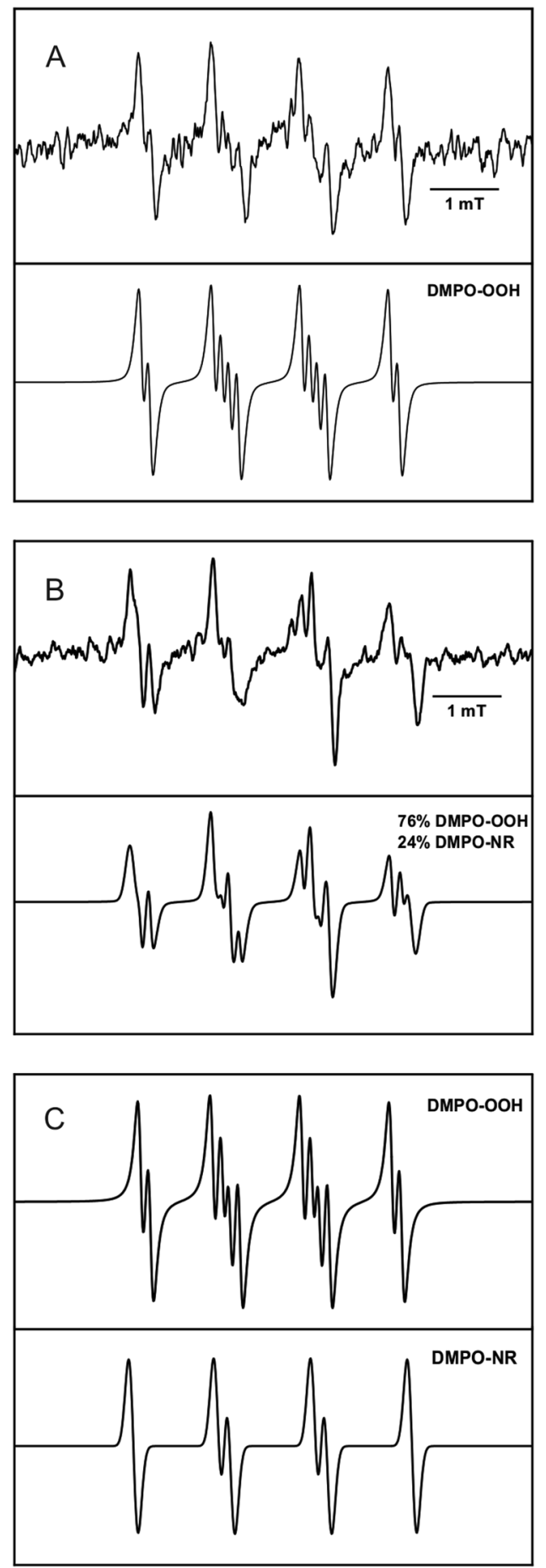

Fig. 6 EPR spectra of detected (upper line) and simulated (lower line) DMPO adducts in the samples containing: a A2E in $80 \%$ DMSO after $30 \mathrm{~min}$ of blue-light irradiation. Hyperfine splitting constants were calculated as: $a_{\mathrm{N}}=12.80 \mathrm{G}, a_{\mathrm{H}}{ }^{\beta}=10.37 \mathrm{G}$, and $a_{\mathrm{H}}^{\gamma}=1.25 \mathrm{G} ; \mathbf{b}$ A2E and BSA in $80 \%$ DMSO after $30 \mathrm{~min}$ of blue-light irradiation. c Simulations of individual DMPO spin adducts found in the A2E and BSA sample. Hyperfine splitting constants were calculated as: $a_{\mathrm{N} 1}=12.95 \mathrm{G}, \quad a_{\mathrm{H} 1}^{\beta}=10.44 \mathrm{G}, \quad a_{\mathrm{H}}^{\gamma}=1.44 \mathrm{G}, \quad a_{\mathrm{N} 2}=14.01 \mathrm{G}$, and $a_{\mathrm{H} 2}{ }^{\beta}=12.28 \mathrm{G}$ 
Fig. 7 Kinetics (a) and accumulation rates $(\mathbf{b})$ of DMPO-radical adducts formation in the samples containing A2E or BSA or A2E and BSA in $80 \%$ DMSO upon blue-light irradiation. Sample containing A2E and BSA was also blue light-irradiated with 500 units/mL of superoxide dismutase
A

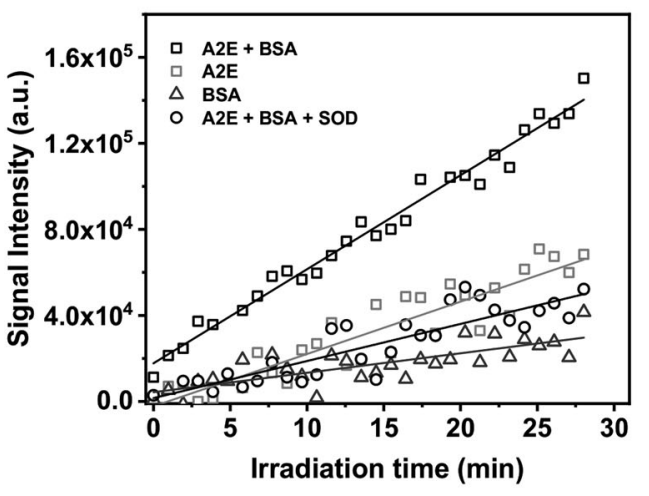

B

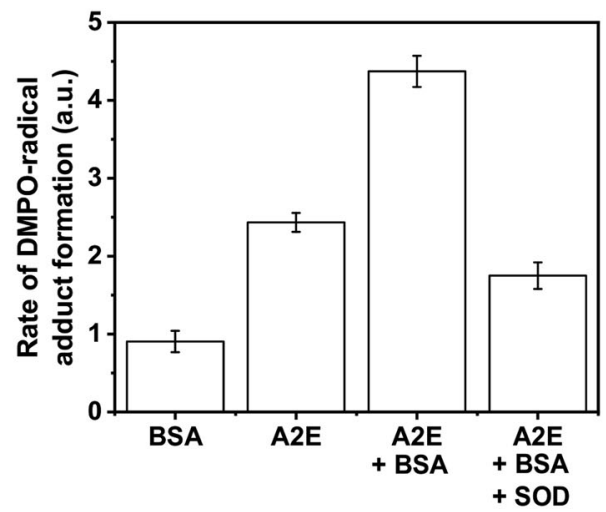

by complexation of this bis-retinoid with BSA. A possible mechanism for the photoformation of superoxide anion by $\mathrm{A} 2 \mathrm{E}$ could involve the following reactions:

$$
\begin{gathered}
\mathrm{A} 2 \mathrm{E}+\mathrm{h} \nu \rightarrow{ }^{1} \mathrm{~A} 2 \mathrm{E} \rightarrow{ }^{3} \mathrm{~A} 2 \mathrm{E} ;{ }^{3} \mathrm{~A} 2 \mathrm{E}+\mathrm{A} 2 \mathrm{E} \rightarrow \mathrm{A}^{2} \mathrm{E}^{+\cdot} \\
+\mathrm{A} 2 \mathrm{E} ; \mathrm{A} 2 \mathrm{E}^{-\cdot}+\mathrm{O}_{2} \rightarrow \mathrm{A} 2 \mathrm{E}+\mathrm{O}_{2}^{-\cdot} .
\end{gathered}
$$

In this scheme, self-quenching of the excited triplet state of A2E is responsible for the formation of its radical forms. Such processes have been observed for other photosensitizers, including rose Bengal [52]. The reactivity of the semireduced

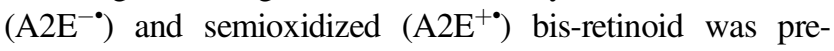
viously studied by pulse radiolysis [51]. That study clearly showed that the anion radical was relatively long-lived and interacted efficiently with dioxygen (the corresponding rate constant was determined to be $3 \times 10^{8} \mathrm{M}^{-1} \mathrm{~s}^{-1}$ ) forming superoxide anion, while the cation radical was short-lived and decayed rapidly. Of course, in the presence of an appropriate electron donor, the efficiency of the formation of the anion radical of $\mathrm{A} 2 \mathrm{E}$ is expected to increase. BSA could serve as such an electron donor, as suggested by results of the spin trapping in samples containing BSA/A2E. To rule out possible role of singlet oxygen in the formation of the detected spin adducts, the spin trapping experiments were also carried out after addition of efficient quenchers of singlet oxygenazide or DABCO. The corresponding results are shown in Supplementary material (Fig. 4S). It is apparent that azide not only increases the formation of the detected spin adduct by a factor of two (Fig. 4S C), but also modifies its spectral parameters (Fig. 4S A, B). As evident by simulation of the observed spectra, additional spin adduct is formed in the presence of azide (Fig. 4S A, B). Its spectral parameters are consistent with DMPO- $\mathrm{N}_{3}$ [53]. The observed data can be explained by assuming that azide acts as an electron donor for the excited triplet state of A2E:

${ }^{3} \mathrm{~A} 2 \mathrm{E}+\mathrm{N}_{3}^{-} \rightarrow \mathrm{A}^{2} \mathrm{E}^{-\cdot}+\mathrm{N}_{3}^{-} ; \mathrm{N}_{3}^{-}+\mathrm{DMPO} \rightarrow \mathrm{DMPO}-\mathrm{N}_{3}$.

Similar processes have been demonstrated in case of methylene blue used as a photosensitizer [54]. Importantly, when DABCO was added, no significant changes of the spin adducts were observed (no data shown). Our data clearly suggest that photo-induced electron transfer reactions (Type I photochemistry) determine the observed formation of superoxide anion and other radicals. It can be postulated that in the presence of azide, the azide radical is formed via electron transfer from the azide anion to the excited triplet state of A2E. The generated A2E anion radical via interaction with dioxygen forms additional superoxide anion (Fig. 4S C), while azide radical decays via unidentified reactions.

\section{Photooxidation of Albumin Mediated by A2E in Model Systems}

Photoreactivity of A2E was also examined as its ability to oxidize proteins. A simple model system consisting of BSA and $\mathrm{A} 2 \mathrm{E}$ in $\mathrm{H}_{2} \mathrm{O}$ or $\mathrm{D}_{2} \mathrm{O}$ micellar and non-micellar systems was employed. Addition of the fluorogenic probe CBA to samples containing BSA and A2E, right after irradiation of the samples with blue light, resulted in a slow formation of the highly fluorescent hydroxycoumarin $(\mathrm{COH})$ - product of the interaction of protein hydroperoxides with CBA $[37,38]$. The kinetics of the $\mathrm{COH}$ accumulation suggests that the initial protein hydroperoxide formation is faster in $\mathrm{D}_{2} \mathrm{O}$ than in $\mathrm{H}_{2} \mathrm{O}$, particularly in non-micellar model systems (Figs. 8, 9). Although addition of sodium azide did not inhibit the initial rate of $\mathrm{COH}$ formation, the amount of hydroxycoumarin accumulated after longer irradiation times was significantly lower than in the absence of azide (Fig. 10). This unexpected result could be explained assuming different penetration of BSA by azide ions at different state of the protein photosensitized oxidation. It cannot be ruled out that while the intact BSA is mostly impermeable for azide, oxidation of the protein by singlet oxygen and free radicals makes it more accessible for negatively charged ions such as azide.

Inhibition of protein hydroperoxides formation by sodium azide and slower oxidation of BSA in $\mathrm{H}_{2} \mathrm{O}$ 
Fig. 8 Evolution of the $\mathrm{COH}$ fluorescence in the samples containing $50 \mu \mathrm{M}$ A2E and $100 \mu \mathrm{M}$ BSA in $\mathrm{D}_{2} \mathrm{O}$-micellar model system (a) or $\mathrm{D}_{2} \mathrm{O}$-nonmicellar model system (b) and $\mathrm{H}_{2} \mathrm{O}$-micellar model system (c) or $\mathrm{H}_{2} \mathrm{O}$-non-micellar model system (d) after irradiation with $440 \mathrm{~nm}$ light for selected time intervals

Fig. 9 Concentration of albumin hydroperoxides generated in samples containing $50 \mu \mathrm{M}$ A2E and $100 \mu \mathrm{M}$ BSA in micellar model systems (a) and non micellar model systems (b) after irradiation with $440 \mathrm{~nm}$ light for selected time intervals
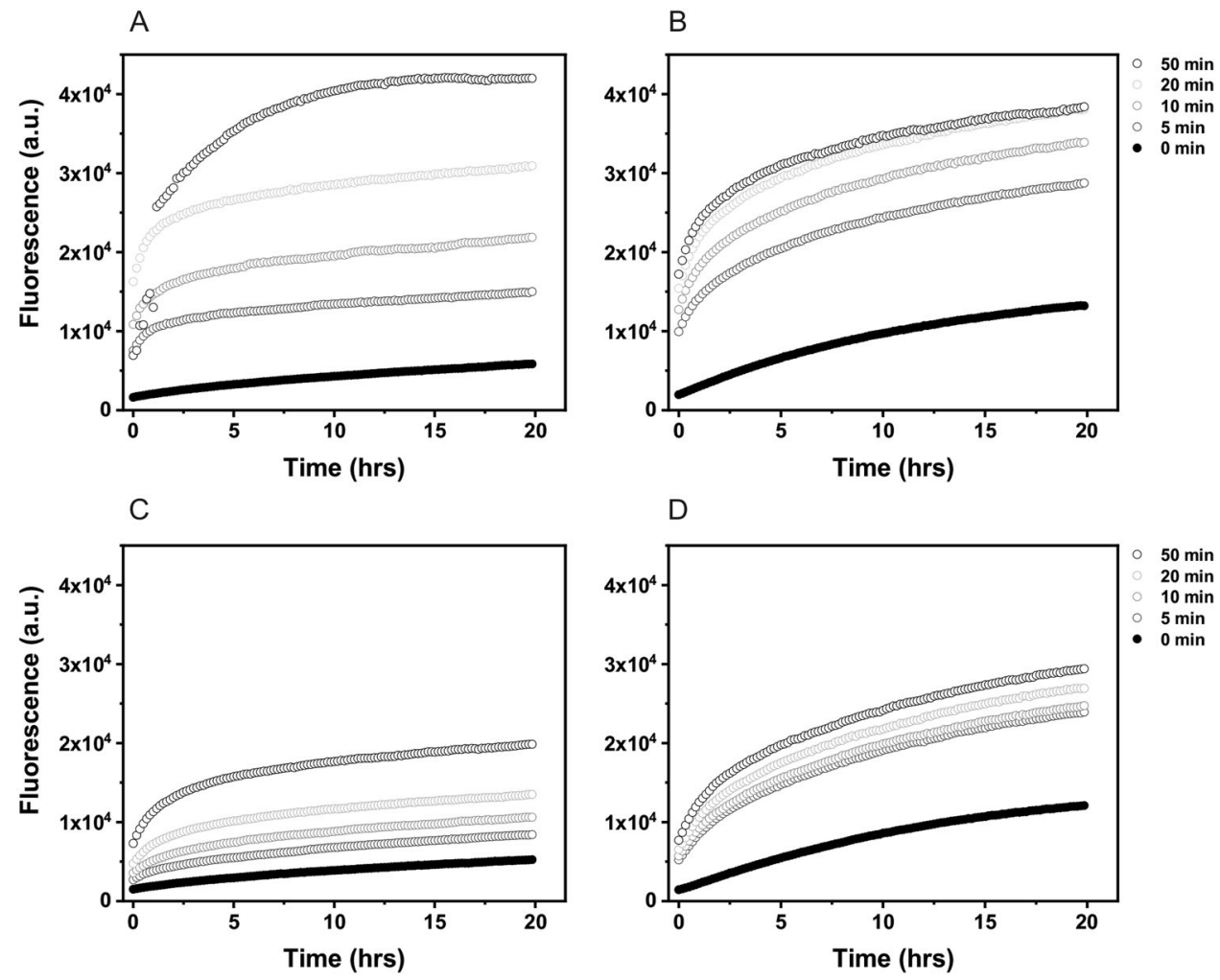

A

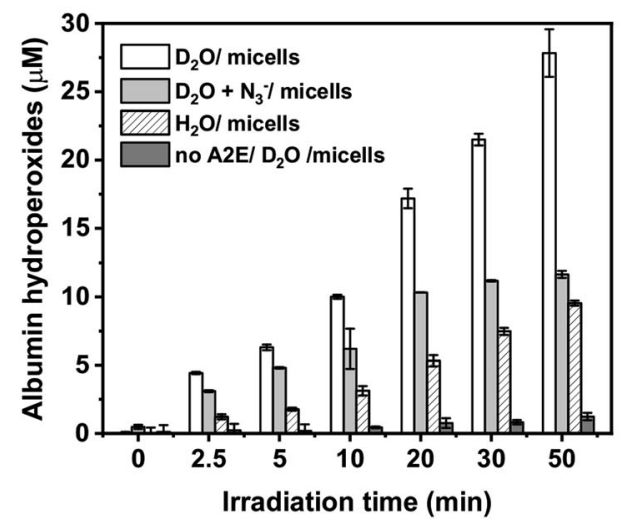

B

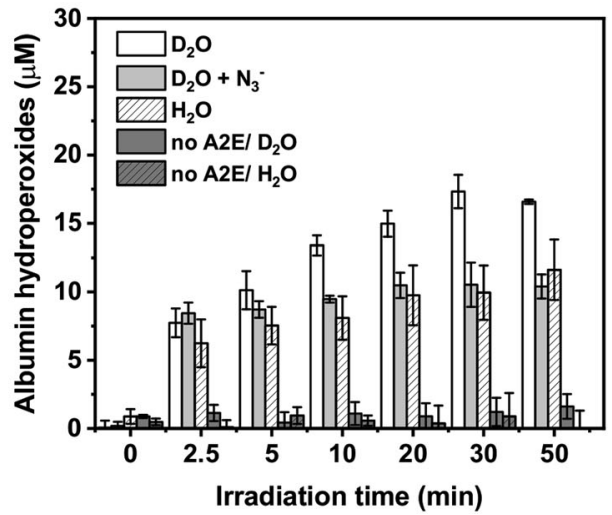

compared to $\mathrm{D}_{2} \mathrm{O}$ confirm the involvement of singlet oxygen in the protein photooxidation mediated by A2E.

\section{Fluorescence Measurements}

The interaction of A2E with BSA was studied by measuring the BSA fluorescence as a function of increasing concentration of A2E. To minimize aggregation of A2E in water and to ensure that the optical absorption of A2E and BSA during the titration experiment was acceptable for the analysis, concentrations of BSA and A2E were reduced 20fold, in comparison with our other experiments. An exponential decay fitted to the obtained data (Supplementary Fig. 1S) demonstrated that dissociation constants for the A2E-BSA complex were comparable in solution and in the micellar system, with the corresponding values being $K_{\mathrm{d}}=1.1 \times 10^{-5} \mathrm{M}$ and $K_{\mathrm{d}}=9.2 \times 10^{-6} \mathrm{M}$, respectively. Under the conditions used, binding of A2E to BSA was not disrupted by the presence of the detergent. The disrupting effect of the detergent was observed at higher concentrations of reagents (data not shown); however, at such higher concentrations, the OD of the sample was too high. A detail analysis of this issue requires further investigation by other techniques, such as differential scanning calorimetry. 
Photooxidation of albumin mediated by A2E was monitored by measuring the protein fluorescence in $\mathrm{D}_{2} \mathrm{O}$ after excitation at 278,325 , and $365 \mathrm{~nm}$, which corresponds to absorption maxima of tryptophan, $\mathrm{N}^{\prime}$-formylkynurenine, and kynurenine, respectively [39]. Kynurenines are oxidation products of Trp residues formed as a result of their interaction with singlet oxygen [55]. Data shown in Fig. 11 demonstrate that addition of A2E to solution of BSA caused quenching of the protein intrinsic fluorescence. Quenching

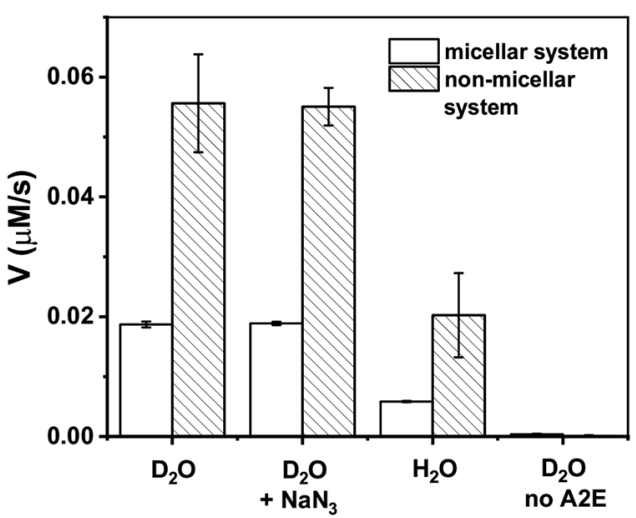

Fig. 10 The initial formation of the albumin hydroperoxides (V) generated in the samples containing $50 \mu \mathrm{M} \mathrm{A} 2 \mathrm{E}$ and $100 \mu \mathrm{M}$ BSA in micellar model systems and non-micellar model systems after irradiation with $440 \mathrm{~nm}$ light of the tryptophan fluorescence may suggest that A2E binds to the protein site where Trp is located. After blue-light irradiation of the sample, which resulted in photobleaching of A2E, the characteristic emission of $\operatorname{Trp}$ at $350 \mathrm{~nm}$ moderately increased. Further irradiation of the sample with blue light brought about a decrease of the $350 \mathrm{~nm}$ emission, accompanied by an increase of the kynurenine emission in near visible region. Kynurenine is known to be a weaker fluorescence emitter and its fluorescence at $445 \mathrm{~nm}$ had lower intensity than fluorescence of $\mathrm{N}^{\prime}$-formylkynurenine at $\sim 424 \mathrm{~nm}$. Control experiments, in which BSA was irradiated with blue light, without A2E, showed no increase of the emission in the visible region (data not shown). These results confirmed that even after photobleaching of A2E, singlet oxygen was generated by excitation of its photodegradation products leading to further oxidation of BSA.

Additional experiments on A2E photodegradation have been performed using UV-Vis spectrophotometry. The absorption spectra recorded during irradiation of $\mathrm{A} 2 \mathrm{E}$ in the presence of $\mathrm{BSA}$ in $\mathrm{PB}-\mathrm{D}_{2} \mathrm{O}$ with blue light demonstrated that after 1 min irradiation almost all of $\mathrm{A} 2 \mathrm{E}$ was photobleached (Supplementary Fig. 3S B). Absorption spectra of $\mathrm{A} 2 \mathrm{E}$ in the micellar system (in the absence of BSA) showed that under such conditions this photoprocess is significantly slower. Thus, although photobleaching of A2E was also observed, even after irradiation of the sample for $10 \mathrm{~min}$,
Fig. 11 Fluorescence spectra of A2E (a), BSA (b), and tryptophan derivatives: $\mathrm{N}$ '-formylkynurenine (c) and kynurenine (d) in $\mathrm{PB}-\mathrm{D}_{2} \mathrm{O}$, recorded before (black lines) and after photooxidation mediated by $\mathrm{A} 2 \mathrm{E}$ at selected time intervals. The excitation wavelengths are given in the top left-hand corners. Emission spectra of tryptophan and its derivatives before the addition of A2E to the BSA sample are marked as black dotted lines
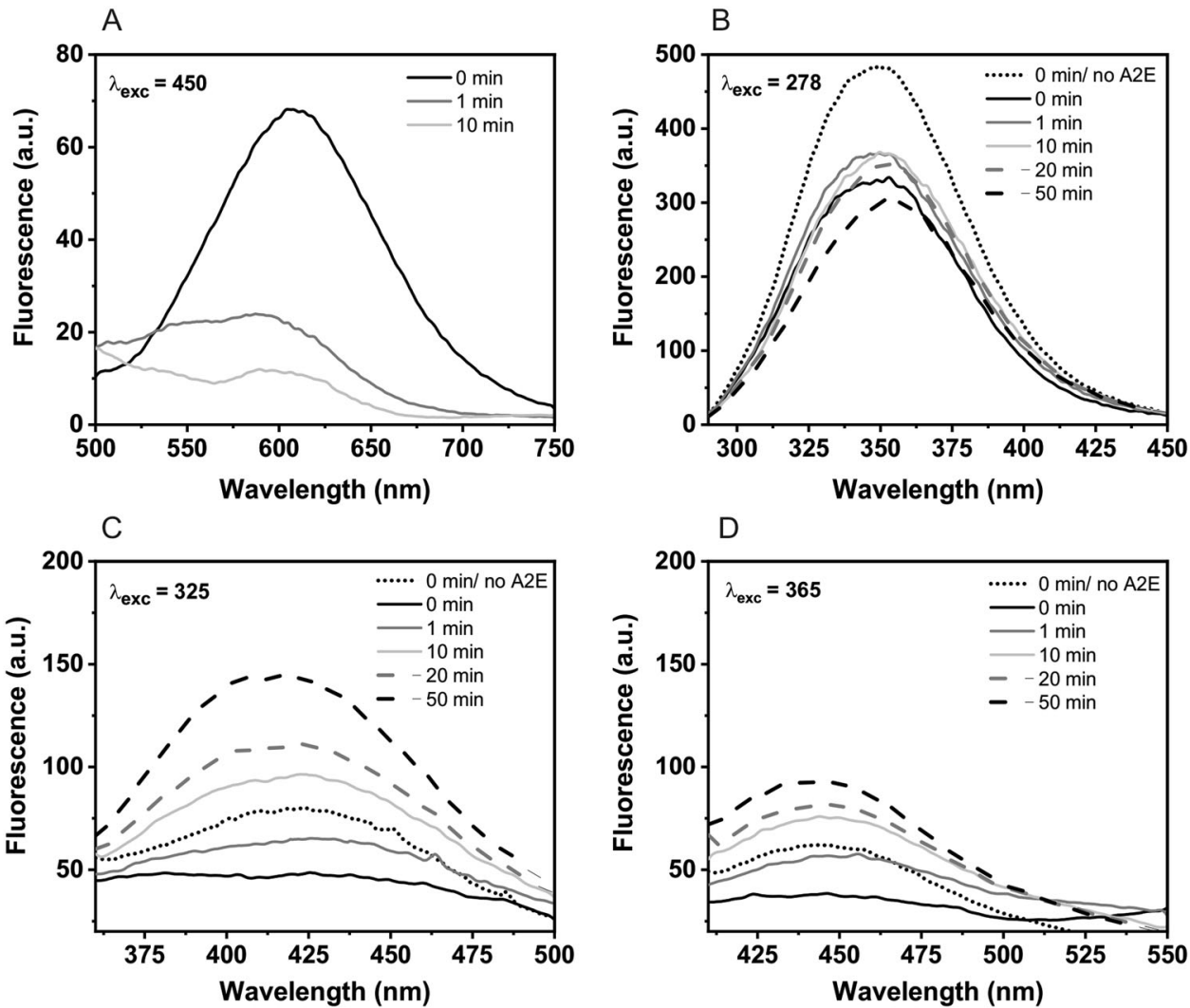
the photobleaching of A2E was only partial (Supplementary Fig. 3S A). Photobleaching of A2E is accompanied by accumulation of its photodegradation products, which is apparent at $290 \mathrm{~nm}$ (Supplementary Fig. 3S A, C). This photodegradation product might be formed as a result of an internal double bond rearrangement in $\mathrm{A} 2 \mathrm{E}$ molecules, which could be induced by electron transfer processes. It appears that photodegradation of A2E only partially depends on oxygen since it also occurred under conditions, in which oxygen content was greatly reduced by saturating the sample for $2.5 \mathrm{~h}$ with argon (Supplementary Fig. 3S C). Nevertheless, our data indicate that both oxygen and BSA accelerated the photodegradation and photooxidation of A2E.

\section{Circular Dichroism (CD)}

As shown in Supplementary material (Fig. 2S), CD spectrum of BSA, exhibits a characteristic secondary structure with peaks of the $\alpha$-helix (positive ellipticity at $192 \mathrm{~nm}$ ) and a double-negative ellipticity (at 208 and $222 \mathrm{~nm}$ ). In the presence of $0.8 \%$ acetonitrile, a slight reduction in negative ellipticity and an increase of the $192 \mathrm{~nm}$ band was observed. Following addition of $\mathrm{A} 2 \mathrm{E}$ or irradiation of the protein in the presence of this bis-retinoid had no significant effect on the secondary structure of BSA. No changes in the recorded $\mathrm{CD}$ spectra of the secondary structure indicate that during the photooxidation of BSA mediated by $\mathrm{A} 2 \mathrm{E}$, no denaturation of the protein occurred.

\section{Summary and Conclusions}

In conclusion, results of this study show that oxidizing photoreactivity of A2E is enhanced after complexation with BSA. Absorption spectra of A2E and changes in the protein intrinsic fluorescence, induced by titration with increasing concentration of $\mathrm{A} 2 \mathrm{E}$, demonstrate the formation of a noncovalent complexes of $\mathrm{A} 2 \mathrm{E}$ with albumin (the corresponding dissociation constant was determined to be $1.1 \times 10^{-5} \mathrm{M}$ ), which could be partially disturbed by the presence of a detergent. Significant quenching of the tryptophan fluorescence in BSA suggests that A2E may bind to the protein site where Trp residues are located. Quantum yield of singlet oxygen production by DDM-solubilized $\mathrm{A} 2 \mathrm{E}$ in $\mathrm{D}_{2} \mathrm{O}$ is relatively low and was determined to equal $1.9 \%$. Complexation of A2E by BSA significantly reduced the photogeneration of singlet oxygen by the bis-retinoid. On the other hand, the photoexcited A2E complexed by BSA generated free radicals with almost twofold higher efficiency than A2E in a homogeneous system. Superoxide anion was the main free radical generated by A2E-BSA. Simulation of the observed EPR spectra indicates that in the presence of BSA, an additional nitrogen-centered radical was photogenerated, which could result from BSA-mediated degradation of A2E. Aerobic photoexcitation of A2E-BSA complexes resulted in the formation of protein hydroperoxides, with the rate being faster in samples without the detergent. The inhibiting effect of sodium azide and the enhancement of $\mathrm{H}_{2} \mathrm{O}$ exchange for $\mathrm{D}_{2} \mathrm{O}$ suggest at least partial involvement of singlet oxygen in this process. This was confirmed by detecting characteristic fluorescence of the photoxidized BSA, consistent with the formation of $\mathrm{N}^{\prime}$-formylkynurenine and kynurenine, known singlet oxygen-dependent oxidation of tryptophan residues. Although A2E was photo-bleached during the first few minutes of blue-light irradiation, the photooxidation of BSA continued, suggesting that products of A2E photodegradation were also able to mediate the photooxidation process. The results from CD measurements indicated that the secondary structures of BSA practically did not change after photooxidation mediated by $\mathrm{A} 2 \mathrm{E}$, suggesting that no detectable denaturation of the protein occurred.

The ability of $\mathrm{A} 2 \mathrm{E}$ to oxidize model protein upon excitation with blue light suggests that the pyridinium bisretinoid may also oxidatively modify cellular proteins and change their key properties. Irreversible oxidative modifications, caused by retinoids, accumulated with age may have profound effect on the morphology and functions of retinal cells. Such alterations, occurring in the case of protein constituents of the RPE cytoskeleton, could have significant impact on nanomechanical properties of the cells, which are important for proper function of the human photoreceptor/RPE complex [56]. Although chronic oxidative stress may disturb many biological functions of RPE/photoreceptor complex, the key molecular targets that are subjected to oxidative modifications remain mostly unknown. We consider changes in the cytoskeleton of human RPE cells as one of the most sensitive indicators of oxidative modifications, which accompany chronic phototoxicity [29, 57]. Future research should focus on identification of the cytoskeletal proteins that might be oxidatively modified under chronic oxidative stress conditions, leading to disruption of key functions of the RPE/ photoreceptor complex.

Acknowledgements This work was supported by National Science Centre, Poland (Grants no 2018/31/N/NZ1/01639 and 2013/08/A/ NZ1/00194). We would like to thank Professor Andrzej Gorecki for the CD measurements. We are grateful to Professor Adam Sikora for providing us with the CBA probe and to Professor Howard Halpern for providing us with the $\mathrm{mHCTPO}$ nitroxide probe.

\section{Compliance with Ethical Standards}

Conflict of Interest The authors declare that they have no conflict of interest.

Publisher's note Springer Nature remains neutral with regard to jurisdictional claims in published maps and institutional affiliations. 
Open Access This article is licensed under a Creative Commons Attribution 4.0 International License, which permits use, sharing, adaptation, distribution and reproduction in any medium or format, as long as you give appropriate credit to the original author(s) and the source, provide a link to the Creative Commons license, and indicate if changes were made. The images or other third party material in this article are included in the article's Creative Commons license, unless indicated otherwise in a credit line to the material. If material is not included in the article's Creative Commons license and your intended use is not permitted by statutory regulation or exceeds the permitted use, you will need to obtain permission directly from the copyright holder. To view a copy of this license, visit http://creativecommons. org/licenses/by/4.0/.

\section{References}

1. Boulton, M., Dontsov, A., Jarvis-Evans, J., Ostrovsky, M., \& Svistunenko, D. (1993). Lipofuscin is a photoinducible free radical generator. J. Photochem. Photobiol. B Biol., 19, 201-204.

2. Rozanowska, M., Jarvis-Evans, J., Korytowski, W., Boulton, M., Burke, J., \& Sarna, T. (1995). Blue light-induced reactivity of retinal age pigment. J. Biol. Chem., 270, 18825-18830.

3. Wassell, J., Davies, S., Bardsley, W., \& Boulton, M. (1999). Photoreactivity of the retinal age pigment lipofuscin. J. Biol. Chem., 274, 23828-23832.

4. Dontsov, A., Glickman, R., \& Ostrovsky, M. (1999). Retinal pigment epithelium pigment granules stimulate the photooxidation of unsaturated fatty acids. Free Radical Biol. Med., 26, 1436-1446.

5. Eldered, G. (1995). Lipofuscin fluorophore inhibits lysosomal protein degradation and may cause early stages of macular degeneration. Gerontology, 41, 15-26.

6. Bermann, M., Schutt, F., Holz, F., \& Kopitz, J. (2001). Does A2E, a retinoid component of lipofuscin and inhibitor of lysosomal degradative functions, directly affect the activity of lysosomal hydrolases? Exp. Eye Res., 72, 191-195.

7. Olchawa, M., Furso, J., Szewczyk, G., \& Sarna, T. (2017). Lipofuscin-mediated photic stress inhibits phagocytic activity of ARPE-19 cells; effect of donors' age and antioxidants. Free Radic. Res., 51(9-10), 799-811.

8. De Laey, J., \& Verougstraete, C. (1995). Hyperlipofuscinosis and subretinal fibrosis in Stargardt's disease. Retina, 15(5), 399-406.

9. Petrukhin, K., Koisti, J., \& Bakall, B., et al. (1998). Identification of the gene responsible for Best macular dystrophy. Nat. Genet., 19, 241-247.

10. Young, R. (1987). Pathophysiology of age-related macular degeneration. Surv. Ophthalmol., 31, 291-306.

11. Beatty, S., Koh, H., Phil, M., Henson, D., \& Boulton, M. (2000). The role of oxidative stress in the pathogenesis of age-related macular degeneration. Surv. Ophthalmol., 45(2), 115-134.

12. Winkler, B., Boulton, M., Gottsch, J., \& Sternberg, P. (1999). Oxidative damage and age-related macular degeneration. Mol. Vis., 5, 32.

13. Davies, S., Elliott, M., Floor, E., Truscott, T., Zareba, M., Sarna, T., Shamsi, F., \& Boulton, M. (2001). Photocytotoxicity of lipofuscin in human retinal pigment epithelial cells. Free Radical Biol. Med., 31(2), 256-265.

14. Kennedy, C., Rakoczy, P., \& Constable, I. (1995). Lipofuscin of the retinal pigment epithelium: a review. Eye, 9, 763-771.

15. Liu, J., Itagaki, Y., Ben-Shabat, S., Nakanishi, K., \& Sparrow, J. (2000). The biosynthesis of A2E, a fluorophore of aging retina, involves the formation of the precursor, A2-PE, in the photoreceptor outer segment membrane. J. Biol. Chem., 275(38), 29354-29360.
16. Sakai, N., Decatur, J., Nakanishi, K., \& Eldred, G., et al. (1996). Ocular age pigment "A2-E": an unprecedented pyridinium bisretinoid. J. Am. Chem. Soc., 118, 1559-1560.

17. Ben-Shabat, S., Parish, C., Hashimoto, M., Liu, J., Nakanishi, K., \& Sparrow, J. (2001). Fluorescent pigments of the retinal pigment epithelium and age-related macular degeneration. Bioorg. Med. Chem. Lett., 11(12), 1533-1540.

18. Haralampus-Grynaviski, N., Lamb, L., Clancy, C., Skumatz, C., Burke, J., Sarna, T., \& Simon, J. (2003). Spectroscopic and morphological studies of human retinal lipofuscin granules. PNAS, 100(6), 3179-3184.

19. Roberts, J., Kukielczak, B., Hu, D., Miller, D., Bilski, P., Sik, R., Motten, A., \& Chignell, C. (2002). The role of A2E in prevention or enhancement of light damage in human retinal pigment epithelial cells. Photochem. Photobiol., 75(2), 184-190.

20. Lakkaraju, A., Finnemann, S., \& Rodriguez-Boulan, E. (2007). The lipofuscin fluorophore A2E perturbs cholesterol metabolism in retinal pigment epithelial cells. Proc. Natl Acad. Sci. USA, 104 (26), 11026-11031.

21. Holtz, F., et al. (1999). Inhibition of lysosomal degradative functions in RPE cells by a retinoid component of lipofuscin. Investig. Ophthalmol. Vis. Sci., 40(3), 737-743.

22. Bergmann, M., Schutt, F., Kopitz, J., Eldred, G., Kruse, F., Volcker, H., \& Cantz, M. (2004). Inhibition of the ATP-driven proton pump in RPE lysosomes by the major lipofuscin fluorophore A2-E may contribute to the pathogenesis of age-related macular degeneration. FASEB J., 18(3), 562-564.

23. Wielgus, A., Chignell, C., Ceger, P., \& Roberts, J. (2010). Comparison of A2E cyto- and phototoxicity with all-trans-retinal in human retinal pigment epithelial cells. Photochem. Photobiol., 86(4), 781-791.

24. Pawlak, A., Wrona, M., Rozanowska, M., Zareba, M., Lamb, L., Roberts, J., Simon, J., \& Sarna, T. (2003). Comparison of the aerobic photoreactivity of A2E with its precursor retinal. Photochem. Photobiol., 77(3), 253-258.

25. Sparrow, J., Nakanishi, K., \& Parish, C. (2000). The lipofuscin fluorophore A2E mediates blue light-induced damage to retinal pigmented epithelial cells. Invest. Ophthalmol. Vis. Sci., 41, 1981-1989.

26. Schutt, F., Davies, S., Kopitz, J., Holz, F., \& Boulton, M. (2000). Photodamage to human RPE cells by A2-E, a retinoid component of lipofuscin. Investig. Ophthalmol. Vis. Sci., 41, 2303-2308.

27. Xu, Q., Huff, L., Fujii, M., \& Griendling, K. (2017). Redox regulation of the actin cytoskeleton and its role in the vascular system. Free Radical Biol. Med., 109, 84-107.

28. Cousins, S., Marin-Castano, M., Csaky, K., \& Espinosa-Heidmann, D. (2006). Pathogenesis of early age-related macular degeneration (AMD): a new hypothesis. In O. R. Ioseliani ed, New developments in eye research (pp. 1-45). Hauppauge, NY: Nova Science Publishers.

29. Wiktor, A., Sarna, M., Wnuk, D., \& Sarna, T. (2018). Lipofuscinmediated photodynamic stress induces adverse changes in nanomechanical properties of retinal pigment epithelium cells. Sci. Rep., 8, 17929.

30. Parish, C., Hashimoto, M., Nakanishi, K., Dillon, J., \& Sparrow, J. (1998). Isolation and one-step preparation of A2E and iso-A2E, fluorophores from human retinal pigment epithelium. Proc. Natl Acad. Sci. USA, 95(25), 14609-14613.

31. Halpern, H., Peric, M., Nguyen, T., \& Spencer, D. (1990). Selective isotopic labeling of a nitroxide spin label to enhance sensitivity for T2 oximetry. J. Magn. Reson., 90, 40-51.

32. Rozanowska, M., Jarvis-Evans, J., Korytowski, W., Boulton, M., Burke, J., \& Sarna, T. (1995). Blue light-induced reactivity of retinal age pigment. In vitro generation of oxygen-reactive species. J. Biol. Chem., 270(32), 18825-18830. 
33. Redmond, R., \& Gamlin, J. (1999). A compilation of singlet oxygen yields from biologically relevant molecules. Photochem. Photobiol., 70(4), 391-475.

34. Buettner, G., \& Oberley, L. (1978). Considerations in spin trapping of superoxide and hydroxyl radical in aqueous systems using 5,5-dimethyl-1-pyrroline-1-oxide. Biochem. Biophys. Res. Commun., 83(1), 69-74.

35. Fee, J., Valentine, J. (1997). Chemical and physical properties of superoxide. In Superoxide and superoxide dismutases (Michelson, A., McCord, J., Fridovich, I. ed), Academic Press, New York, pp. 19-60.

36. Monroe, B. (1985). Singlet oxygen in solution: lifetimes and reaction rate constants. In A. Firmer ed, Singlet O2 Vol. 1: physical-chemical aspects (pp. 177-224). Boca Raton, FL: CRC.

37. Zielonka, J., Sikora, A., Hardy, M., Joseph, J., Dranka, B., \& Kalyanaraman, B. (2012). Boronate probes as diagnostic tools for real time monitoring of peroxynitrite and hydroperoxides. Chem. Res. Toxicol., 25(9), 1793-1799.

38. Michalski, R., Zielonka, J., Gapys, E., Marcinek, A., Joseph, J., \& Kalyanaraman, B. (2014). Real-time measurements of amino acid and protein hydroperoxides using coumarin boronic acid. J. Biol. Chem., 289(32), 22536-22553.

39. Fukunaga, Y., Katsuragi, Y., Izumi, T., \& Sakiyama, F. (1982). Fluorescence characteristics of kynurenine and $\mathrm{N}^{\prime}$-formylkynurenine, their use as reporters of the environment of tryptophan 62 in hen egg-white lysozyme. J. Biochem, 92(1), 129-141.

40. Nonell, S., \& Flors, C. (2016). Steady-state and time-resolved singlet oxygen phosphorescence detection in the near-IR. In Singlet oxygen: applications in biosciences and nanosciences 2, (pp. 7-26). Cambridge, UK: RSC.

41. Davis, C., McNeill, K., \& Janssen, E. (2018). Non-singlet oxygen kinetic solvent isotope effects in aquatic photochemistry. Environ. Sci. Technol., 52(17), 9908-9916.

42. Kanofsky, J., Sima, P., \& Richter, C. (2003). Singlet oxygen generation from A2E. Photochem. Photobiol., 77(3), 235-242.

43. Ragauskaite, L., Heckathorn, R., \& Gaillard, E. (2001). Environmental effects on the photochemistry of A2-E, a component of human retinal lipofuscin. Photochem. Photobiol., 74(3), 483-488.

44. Ben-Shabat, S., Itagaki, Y., Jockusch, S., Sparrow, J., Turro, N., \& Nakanishi, K. (2002). Formation of a nonaoxirane from A2E, a lipofuscin fluorophore related to macular degeneration, and evidence of singlet oxygen involvement. Angew. Chem. Int. Ed. Engl., 41(5), 814-817.
45. Sparrow, J., Zhou, J., Ben-Shabat, S., Vollmer, H., Itagaki, Y., \& Nakanishi, K. (2002). Involvement of oxidative mechanisms in blue-light-induced damage to A2E-Laden RPE. Invest. Ophthalmol. Vis. Sci., 43(4), 1222-1227.

46. Skovsen, E., Snyder, J., Lambert, J., \& Ogilby, P. (2005). Lifetime and diffusion of singlet oxygen in a cell. J. Phys. Chem. B., 109 (18), 8570-8573.

47. Roberts, J., Wishart, J., Martinez, L., \& Chignell, C. (2000). Photochemical studies on xanthurenic acid. Photochem. Photobiol., 72(4), 467-471.

48. Buettner, G. (1987). Spin trapping: ESR parameters of spin adducts. Free Radical Biol. Med., 3(4), 259-303.

49. Pawlak, A., Rozanowska, M., Zareba, M., Lamb, L., Simon, J., \& Sarna, T. (2002). Action spectra for the photoconsumption of oxygen by human ocular lipofuscin and lipofuscin extracts. Arch. Biochem. Biophys., 403(1), 59-62.

50. Gaillard, E., Avalle, L., Keller, L., Wang, Z., Reszka, K., \& Dillon, J. (2004). A mechanistic study of the photooxidation of A2E, a component of human retinal lipofuscin. Exp. Eye Res., 79(3), 313-319.

51. Broniec, A., Pawlak, A., Sarna, T., Wielgus, A., Roberts, J., Land, E., Truscott, T., Edge, R., \& Navaratnam, S. (2005). Spectroscopic properties and reactivity of free radical forms of A2E. Free Radical Biol. Med., 38, 1037-1046.

52. Sarna, T., Zajac, J., Bowman, M., \& Truscott, T. (1991). Photoinduced electron transfer reactions of rose bengal and selected electron donors. J. Photochem. Photobiol. A, 60(3), 295-310.

53. Kalyanaraman, B., Janzen, E., \& Mason, R. (1985). Spin trapping of the azidyl radical in azide/catalase $/ \mathrm{H}_{2} \mathrm{O}_{2}$ and various azide/ peroxidase $/ \mathrm{H}_{2} \mathrm{O}_{2}$ peroxidizing systems. J. Biol. Chem., 260(7), 4003-4006.

54. Huang, L., St Denis, T., Xuan, Y., Huang, Y., Tanaka, M., Zadlo, A., Sarna, T., \& Hamblin, M. (2012). Paradoxical potentiation of methylene blue-mediated antimicrobial photodynamic inactivation by sodium azide: role of ambient oxygen and azide radicals. Free Radic. Biol. Med., 53(11), 2062-2071.

55. Bilkis, I., Silman, I., \& Weiner, L. (2018). Generation of reactive oxygen species by photosensitizers and their modes of action on proteins. Curr. Med. Chem., 25(40), 5528-5539.

56. Sarna, M., Olchawa, M., Zadlo, A., Wnuk, D., \& Sarna, T. (2017). The nanomechanical role of melanin granules in the retinal pigment epithelium. Nanomedicine, 13(3), 801-807.

57. Sarna, T., Sarna, M., Pilat, A., \& Olchawa, M. (2014). Atomic force microscopy (AFM) and fluorescence imaging of ARPE-19 cells subjected to sublethal oxidative stress. Investig. Ophthalmol. Vis. Sci., 55(13), 381. 